\title{
Glycosphingolipid metabolism and its role in ageing and Parkinson's disease
}

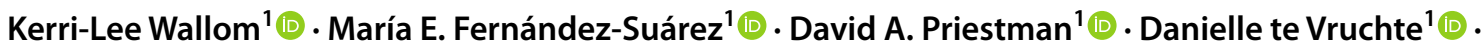

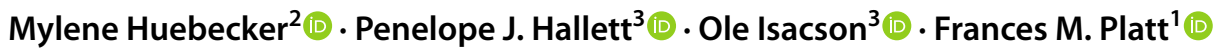

Received: 9 June 2021 / Revised: 22 September 2021 / Accepted: 24 September 2021 / Published online: 10 November 2021

(C) The Author(s) 2021

\begin{abstract}
It is well established that lysosomal glucocerebrosidase gene (GBA) variants are a risk factor for Parkinson's disease (PD), with increasing evidence suggesting a loss of function mechanism. One question raised by this genetic association is whether variants of genes involved in other aspects of sphingolipid metabolism are also associated with PD. Recent studies in sporadic PD have identified variants in multiple genes linked to diseases of glycosphingolipid (GSL) metabolism to be associated with PD. GSL biosynthesis is a complex pathway involving the coordinated action of multiple enzymes in the Golgi apparatus. GSL catabolism takes place in the lysosome and is dependent on the action of multiple acid hydrolases specific for certain substrates and glycan linkages. The finding that variants in multiple GSL catabolic genes are over-represented in PD in a heterozygous state highlights the importance of GSLs in the healthy brain and how lipid imbalances and lysosomal dysfunction are associated with normal ageing and neurodegenerative diseases. In this article we will explore the link between lysosomal storage disorders and PD, the GSL changes seen in both normal ageing, lysosomal storage disorders (LSDs) and $\mathrm{PD}$ and the mechanisms by which these changes can affect neurodegeneration.
\end{abstract}

Keywords Parkinson's disease (PD) · Glycosphingolipid (GSL) · Gangliosides · Ageing · GBA · Lysosomal storage disease (LSD)

\section{Introduction}

Glycosphingolipids (GSLs) are composed of a hydrophobic ceramide moiety linked to a hydrophilic glycan head group [1]. The complexity of GSLs is a result of the diversity of sugars in the head group (the monosaccharide type, number, and linkage) and heterogeneity in both the long-chain base and the fatty acyl moiety of the ceramide (chain length, hydroxylation, and saturation) [1] (Fig. 1). The biosynthesis of GSLs is also complex and begins in the ER with the generation of their precursor, ceramide, through the differential activities of multiple

Frances M. Platt

frances.platt@pharm.ox.ac.uk

1 Department of Pharmacology, University of Oxford, Oxford, UK

2 Institute of Innate Immunity, Biophysical Imaging, Medical Faculty, University of Bonn, Bonn, Germany

3 Neuroregeneration Institute, McLean Hospital, Harvard Medical School, Belmont, MA 02478, USA ceramide synthases (CERS) that generate ceramide backbones with different chain lengths [2,3]. The first step in the biosynthesis of most GSLs is the transfer of glucose to the ceramide backbone on the outer leaflet of an early Golgi compartment, generating glucosylceramide (GlcCer) (Fig. 2). Neutral GSLs are synthesised in the trans Golgi, whereas gangliosides (GSLs containing charged sialic acids) are synthesised luminally in an early Golgi compartment [1]. The regulation of these two branches of GSL biosynthesis is regulated through vesicular and non-vesicular transfer, respectively. If GlcCer moves via vesicular transport through the Golgi stack, it is preferentially used to build gangliosides (starting with GM3). Non-vesicular transfer of GlcCer to late Golgi compartments is mediated by the action of the lipid transfer protein FAPP2 and leads to preferential production of globosides (starting with Gb3) [4]. GSLs have a stable cell-type specific expression pattern and mediate numerous biological functions, such as cell adhesion and migration, cell signalling, proliferation, endocytosis, intracellular transport, inflammation and apoptosis [5]. The biosynthesis, trafficking, and catabolism of GSLs is tightly regulated (Fig. 2). 


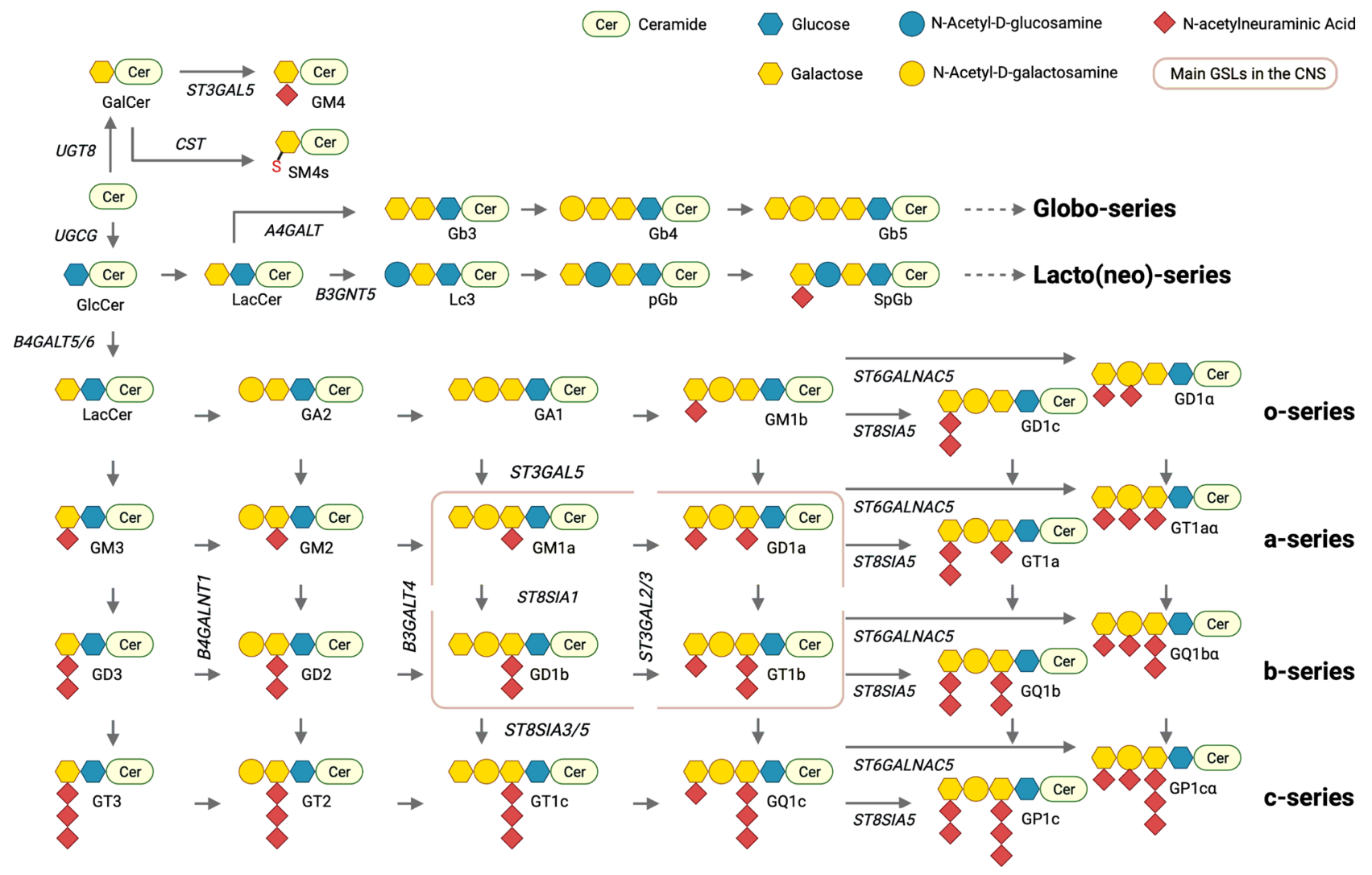

Fig. 1 Simplified scheme of GSL biosynthesis. Major gangliosides expressed in the central nervous system (CNS) in adult mammalian brain are boxed in pink. Biosynthetic enzyme genes are indicated in

Insights into GSL functions and metabolism have arisen in part from the study of inborn errors of metabolism in which genes encoding lysosomal enzymes involved in GSL catabolism are mutated. Typically, these diseases are inherited as autosomal recessive traits [6]. This family of rare diseases are termed lysosomal storage diseases (LSDs) and include Gaucher disease (GBA mutations) and Sandhoff disease (HEXB mutations). All sphingolipid lysosomal storage diseases are multimorbidity diseases and the majority have a neurodegenerative clinical course, emphasising the biological importance of GSLs in the brain. The mammalian brain GSL profile is dominated by gangliosides. The main four gangliosides, GM1a, GD1a, GD1b and GT1b make up $>90 \%$ of GSLs in the brain of all mammals, and reside primarily on the outer leaflet of the plasma membrane (PM) [7].

As mice engineered to be null for GlcCer synthase are embryonically lethal [8], it was hypothesised that there would be no human diseases arising from mutations in GSL biosynthetic genes as they would result in lethality during embryonic development. However, there are ultra-rare diseases of ganglioside biosynthesis that have been identified in Old Amish communities in the USA. For example, blue. GSL names are abbreviated according to Svennerholm [123] and recommended by IUPAC [124]

B4GALNT1 variants, encoding GM2-synthase, lead to a lack of GM2 and higher GSLs (a-series), resulting in a complex form of hereditary spastic paraplegia, and in mice lead to parkinsonism [9]. Mutations in ST3GAL5, encoding GM3 synthase, which initiates the synthesis of all downstream cerebral gangliosides, result in an extremely severe epilepsy syndrome [10].

\section{The link between Gaucher disease and Parkinson's disease}

The first link found between an LSD and PD was the association with Gaucher Disease (GD). Initially clinicians observed an unusually high subset of GD patients as well as their relatives developing parkinsonism over time [11]. In 2009, a major worldwide multi-centre genetic study reported a significant association between mutations in the $G B A$ gene, the genetic cause of GD, and sporadic PD [12]. Subsequently, it was established that $10-15 \%$ of those with heterozygous and homozygous GBA mutations develop $\mathrm{PD}$, a 20-fold increased risk compared to non-carriers [13]. Furthermore, $5-15 \%$ of sporadic PD patients carry a $G B A$ 


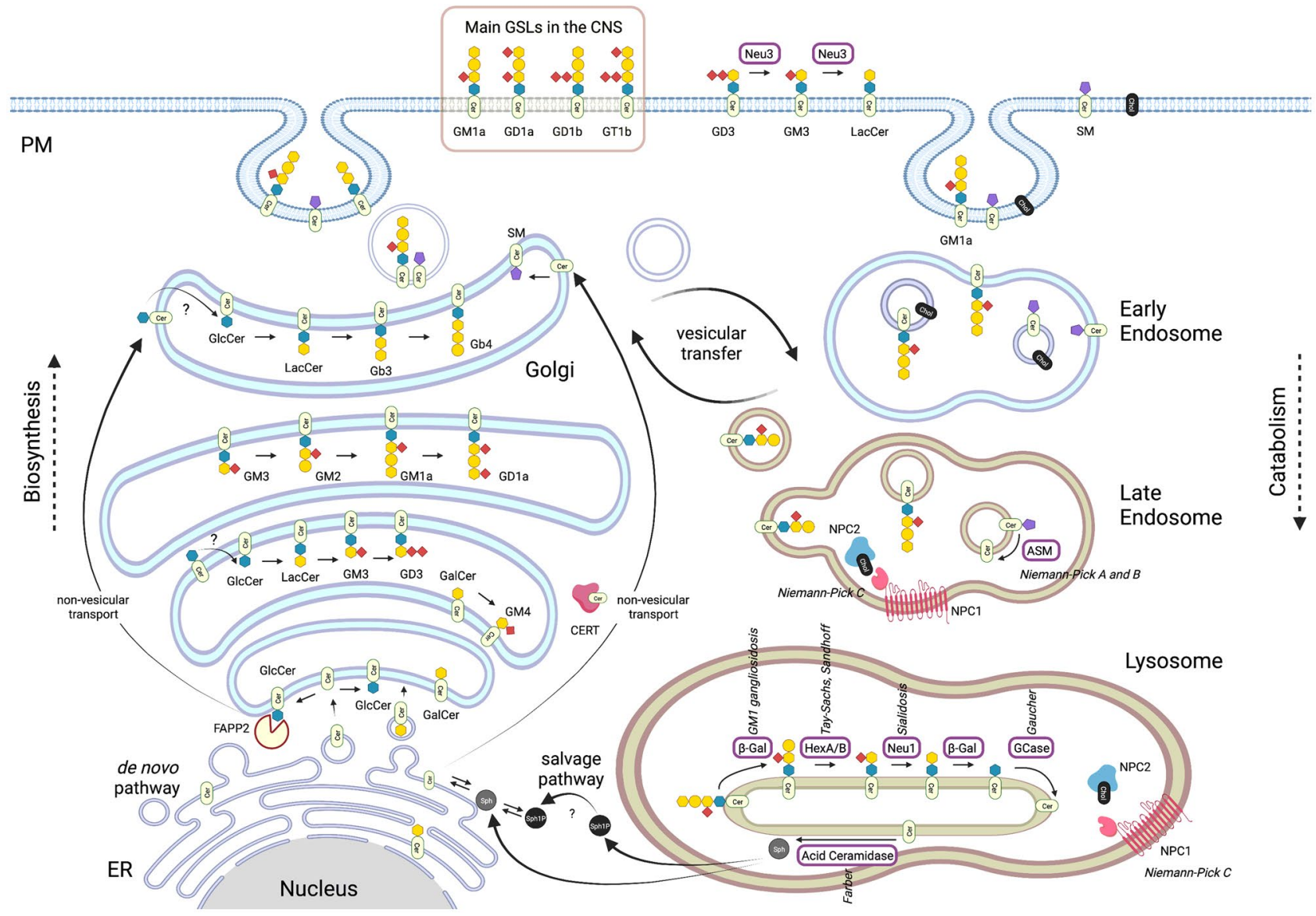

Fig. 2 Metabolism and trafficking of GSLs. Ceramide is synthesised in the ER and transported to the Golgi by vesicular transport where it is converted to GlcCer. Ceramide can also be bound by CERT and transported by non-vesicular pathway to the late Golgi for the synthesis of SM [125]. Also, via a non-vesicular pathway, the transfer protein FAPP2 transports GlcCer from cis to trans golgi and couples it specifically to the synthesis of globosides [126]. GSLs are then carried by vesicular transport to the plasma membrane where they can be remodelled. Upon endocytosis GSLs are degraded into monosaccharides, free fatty acids, and sphingoid bases, which are

mutation and present earlier, meaning $G B A$ is the highest genetic risk factor for developing PD and carrying this gene increases the rate of progression [14].

Homozygous mutations in the $G B A$ gene, encoding the enzyme glucocerebrosidase (GCase), mean the enzyme is unable to degrade its GSL substrates GlcCer and glucosylsphingosine (GlcSph) [15]. It has always been believed that heterozygosity was not associated with storage or pathology, however no systematic studies have been performed on Gaucher carriers as they age to determine if they are more susceptible to certain diseases.

The pathogenic mechanism linking GBA to PD is unclear, but several studies have linked it directly to alpha-synuclein. A key question is whether this association results from gain or loss of enzymatic function. The fact that most GCase recycled for sphingolipid synthesis by the salvage pathway (modified after [127]). ASM, acid sphingomyelinase; $\beta$-Gal, $\beta$-Galactosidase; Cer, ceramide; CERT, ceramide transfer protein; chol, cholesterol; ER, endoplasmic reticulum; FAPP2, phosphatidylinositol-fourphosphate adapter protein 2; GCase, glucocerebrosidase; GlcCer, glucosylceramide; Hex, hexosaminidase; LacCer, lactosylceramide; Neu, neuraminidase; PM, plasma membrane; SM, sphingomyelin; Sph, sphingosine; Sph1P, sphingosine-1-phosphate. The figures were created with BioRender.com

mutations result in misfolded protein could theoretically lead to a gain of function, either directly by causing alphasynuclein aggregation, or by causing ER stress or lysosomal/autophagosomal disruption [16]. Mutant GCase has been found in $75 \%$ of Lewy bodies in post-mortem GBA-PD brain which could suggest it enhances aggregation of alphasynuclein, or alternatively is simply the cell trying to clear it [17]. Supporting the gain of function hypothesis, there are mutations that do not cause GD but do predispose to PD [18]. However, there are null mutations that also predispose to PD, thus suggesting the pathological mechanism is not solely due to gain of function.

There is increasing evidence that it is loss of function of GCase that results in alpha-synuclein aggregation. Mazzulli et al. found that the lipid substrate GlcCer was able to stabilise 
alpha-synuclein oligomeric intermediates in the lysosome, which led to further reduction in GBA activity, resulting in a self-propagating feedback loop, leading to neurodegeneration $[19,20]$. GCase also binds alpha-synuclein in the lysosome, but this interaction is reduced with mutant GCase [20]. A recent study further supported the direct effect on alpha-synuclein, indicating that GCase is able to inhibit lipidinduced alpha-synuclein amyloid formation, and that there is competition between lipid and GCase for alpha-synuclein binding [21].

Rocha et al. found that sustained GCase inhibition (with the chemical inhibitor conduritol B epoxide (CBE)) induces alpha-synuclein aggregation, microglial and $\mathrm{C} 1 \mathrm{q}$ activation in mouse substantia nigra, with GlcCer and GlcSph increases leading to neurodegeneration [22]. This accumulation is cell type specific: both PD brains and CBE treated mice have increased neutral lipid accumulation in dopaminergic neurons and microglia, whereas astrocytes have an overall reduced lipid load [23]. Although a recent study found that reduced GCase activity in mice did not result in alpha-synuclein aggregation alone, but when misfolded alpha-synuclein was present, GCase activity modulated neuronal susceptibility to pathology [24]. In an over-expressing alpha-synuclein mouse model, gene therapy with GCase prevented alpha-synuclein accumulation in the substantia nigra and striatum, and overexpression of GBA prevented alpha-synuclein-mediated dopamine neuron degeneration in rats [25]. Furthermore, in a mutant $G B A$ mouse model, CNS expression of GCase alleviated GlcSph and alpha-synuclein accumulation and, importantly, reversed cognitive impairment [26]. This is supportive of loss of function being the main driver of alpha-synuclein aggregation and subsequent neurodegeneration.

Interestingly, GCase activity is also reduced in sporadic PD patients who do not have GBA mutations [27]. It has been reported that progressive decline of GCase also occurs in normal ageing, and results in an increase in glucosyl sphingosine (GlcSph) in the substantia nigra [28]. Elevated GlcCer has been observed in iPSC-derived dopaminergic neurons from $G B A$ associated PD patients, but studies differ as to whether there is accumulation of GlcCer and GlcSph in the human PD brain [16, 28-30]. In one large study, no association was found between storage of GlcSph and the hyperechogenic area of the substantia nigra, a prodromal PD marker in $G B A$ mutation carriers [31].

Some studies have associated 'severe' $G B A$ mutations with a higher risk of PD in carriers [32, 33] as well as an earlier onset and more rapid cognitive decline [34]. In CSF of PD with $G B A$ mutations, GCase activity was decreased with a concomitant increase in GlcCer, and total alpha-synuclein was lower [30, 34]. This difference was greater in those with 'severe' risk $G B A$ variants than 'mild' or 'low' risk. However, evidence shows there is low penetrance of PD with
$G B A$ variants, suggesting the existence of modifier genes that determine risk for PD [35, 36]. A genome-wide association study (GWAS) in mice identified 17 putative modifier genes, the highest significance being those involved in neuronal excitability (Adk, Dpp10, Ctnnd and Grin2b), and secondly in endolysosomal function and neurodevelopment [36]. A recent large GWAS analysing PD associated genetic risk score, to detect genetic influences on GBA risk and age of onset, found the most significant contributors were genes implicated in lysosomal function, notably $S N C A$ and $C T S B$ [35]. Schierding et al. also found a number of common variants (non-coding snps) that regulate $G B A$ expression and co-regulate modifier genes [37]. Such evidence provides a possible explanation for the variable phenotypes seen in GBA-linked PD.

Several other known genetic risk factors for PD are directly linked to GCase activity. LIMP-2 (GBA trafficking receptor that delivers the enzyme to the lysosome) is encoded by $S C A R B 2$, of which gene variants are associated with PD [38]. These variants were not associated with reduced GCase activity; however, activity was measured in dried blood spots so would not be picked up if the enzyme were mis-localised [39]. In a recent study, GCase was found to be reduced in both $G B A$ and non-GBA PD fibroblasts [40]. The idiopathic PD patients were found to have reduced LIMP-2 protein levels, and this correlated with GCase activity. Similarly, variants in $A T P 10 B$, which encodes a late endo-lysosomal lipid flippase that translocates GlcCer to the cytosolic leaflet, has been associated with PD risk [41]. A number of studies have also linked progranulin (PGRN) with PD. Heterozygous $P G R N$ mutations cause frontotemporal dementia with parkinsonism, and reduced progranulin levels are associated with severity of PD [42-44]. Progranulin is lysosomal and thought to bind GCase leading to reduced GCase activity [45].

\section{Links between PD and multiple LSDs}

Although Gaucher disease is the most extensively researched LSD in the context of PD, a number of other LSDs have been associated with parkinsonism, alpha-synuclein accumulation and substantia nigra pathology. The burden of gene variants associated with lysosomal storage disorders in sporadic PD is very significant [46]. A large genetic association study looked at fifty-four LSD genes in the largest PD whole exome sequencing dataset available. Fifty six percent of PD patients had at least one putative damaging lysosomal storage disorder gene variant and twenty one percent of PD patients carried multiple alleles [46]. As well as those previously linked to PD, the study newly implicated $S L C 17 A 5, A S A H 1$, and CTSD causing Salla disease, Farber lipogranulomatosis, and a neuronal ceroid lipofuscinosis 
variant, respectively. SLC17A5 encodes a lysosomal membrane transporter for sialic acid, $A S A H I$ encodes acid ceramidase, which participates in ceramide metabolism, and $C T S D$ encodes a lysosomal aspartyl proteinase that has been implicated in alpha-synuclein degradation [47]. The overall implication of LSD-associated genes in PD is significant and indicates a link between defective catabolism of GSLs and/ or other lysosomal substrates in PD pathogenesis.

It is interesting to note that in addition to multiple GSL catabolic genes being over-represented in sporadic PD, heterozygous mutations were identified in ST3GAL5, encoding GM3 synthase, which catalyses the first step in ganglioside biosynthesis (Fig. 1). GM3 synthase is a sialyltransferase responsible for the generation of GM3 in the Golgi apparatus. Deficiency leads to loss of complex gangliosides, and accumulation of LacCer and neutral globosides [48], causing an early onset severe epilepsy syndrome [10, 46]. This further underlines the imbalance in ganglioside expression as a potential risk factor in PD.

Alpha-synuclein aggregation has been observed in several LSDs [49]. Increased prevalence of PD has been seen in late onset Fabry Disease patients [50], and the deficient enzyme in Fabry disease, alpha-galactosidase, was found to be reduced in PD leukocytes and PD brain [51, 52]. Significant correlation was seen between decreased alphagalactosidase, increased Gb3 and pathological accumulation of alpha-synuclein [51, 52]. Krabbe disease, caused by mutations in galactocerebrosidase $(G A L C)$, results in accumulation of GalCer, which leads to a similar pattern of alpha-synuclein aggregation in the brain of the mouse model to that seen in the human PD brain [53]. GalCer forms hydrophilic clusters and binds the C-terminus of $\alpha$-synuclein [54]. Furthermore, GALC gene therapy completely prevented alpha-synuclein aggregation in the Krabbe mouse model [54]. GalCer was higher in cerebral cortex of PD patients, and controls with heterozygous GALC mutations had evidence of alpha-synuclein pathology [55]. Sandhoff disease is caused by mutations in HEXB gene, resulting in deficiency in the activities of the enzyme Hexosaminidase A and B, and the accumulation of GM2 and GA2. Sandhoff disease brains have also shown evidence of alpha-synuclein aggregation [56]. Deletion of $H E X B$ results in alpha-synuclein aggregation in mice [57], whereas upregulation of beta-hexosaminidase expression (by AAV gene therapy) and activity in an alphasynuclein rat model prevents alpha-synuclein lipid association and protects dopaminergic neurons [58].

Several studies suggest a link between the $N P C l$ gene mutations and PD. Defects in $N P C 1$ are responsible for $95 \%$ of clinical cases of the autosomal recessive LSD NiemannPick disease type C (NPC). NPC is characterized by lysosomal accumulation of lipids including cholesterol and GSLs, and by reduced lysosomal calcium levels [59]. Lipid accumulation and reduced calcium levels within the lysosome are also present in PD [60, 61]. Furthermore, aberrant phosphorylation of alpha-synuclein and Lewy bodies have been found in several brain regions of NPC patients $[62,63]$. A growing number of reports have identified mutations in one allele of $\mathrm{NPCl}$ in patients diagnosed with $\mathrm{PD}$, parkinsonism or atypical PD, such as progressive supranuclear palsy (PSP) or corticobasal degeneration (CBD) [46, 64-66]. Some of these studies showed common clinical manifestations between NPC and PD, such as supranuclear gaze palsy and dementia [66]. Moreover, a recent study showed subclinical deficits in cognition in $\mathrm{NPCl}$ carriers that correlated with impairment of cholinergic circuits [67]. NPC has not explicitly been identified in genetic association studies of large PD cohorts. Nonetheless, its involvement cannot be ruled out, especially for atypical forms of parkinsonism, including PSP/CBD, for which more studies are needed $[66,68]$.

Mutations in the acid sphingomyelin phosphodiesterase 1 (SMPD1) gene, which is responsible for NiemannPick type A/B, have also been associated with PD [69]. Among PD patients, reduced acid sphingomyelinase activity was associated with a 3.5- to 5.8-year earlier onset of PD [70]. Furthermore, SMPD1 knockout and knockdown resulted in increased alpha-synuclein levels in dopaminergic cell models [70].

One form of the LSD neuronal ceroid lipofuscinosis (NCL), known as Batten disease, is caused by homozygous mutations in the GRN gene, which encodes progranulin (PGRN), a lysosomal glycoprotein. Heterozygous $G R N$ mutations cause frontotemporal dementia with parkinsonism [42]. In PD, it has been demonstrated that reduced levels of progranulin are associated with disease severity [43, 44]. Progranulin gene delivery has been shown to protect dopaminergic neurons in a chemically induced (MPTP) mouse model of Parkinson's disease [71]. PGRN has been shown to interact with GCase, being essential for its activity, which may explain its role in PD [45]. ATP13A2, encoding a predominantly neuronal endolysosomal ATPase, is another gene associated with a different form of NCL [72]. Also called PARK9, autosomal recessive mutations in this ATPase are associated with an early onset PD known as Kufor-Rakeb syndrome [73].

The alpha-synuclein accumulation seen in LSDs and its reversibility by increasing the expression of the GSL related gene or enzyme suggests that proteinopathy might be preceded by GSL dysregulation/lysosomal dysregulation in the course of PD pathogenesis .

\section{GSLs and ageing}

The biggest non-genetic risk factor for PD is ageing. There have been several studies reporting age-related changes in sphingolipids (as well as cholesterol, phosphoinositides and 
Table 1 Enzyme activity changes in ageing mouse [76] and human brain [60]. Arrows indicate significance $p=<0.05$

\begin{tabular}{llllll}
\hline & $\begin{array}{l}\text { glucocerebrosidase } \\
\text { (GBA) }\end{array}$ & $\begin{array}{l}\beta \text {-glucosidase } \\
\text { (GBA2) }\end{array}$ & $\alpha$-galactosidase & $\beta$-hexosaminidase & $\beta$-galactosidase \\
\hline Mouse & $\downarrow$ & $\downarrow$ & - & - & $\downarrow$ \\
Human Controls & $\downarrow$ & - & - & - & $\downarrow$ \\
$\quad$ Substantia Nigra & & - & - & $\downarrow$ & - \\
Human PD & $\downarrow$ & & & & - \\
$\quad$ Substantia Nigra & & & & & $\downarrow$ \\
\hline
\end{tabular}

polyunsaturated fatty acids) in the brain (reviewed in [74, 75]). The associations seen between LSDs and PD led to more in-depth studies of lysosomal enzyme levels and GSL levels in the ageing and PD brain. During human ageing, it was found that GBA activity declined in post-mortem substantia nigra and putamen (Table 1) [60]. The lysosomal enzyme levels of GBA as well as several other lysosomal enzymes (alpha-galactosidase, beta-hexosaminidase, beta-galactosidase and neuraminidase) (see Table 2) were reduced even further in PD patients, and the GSL substrate GlcCer progressively accumulated with age (Table 4) [60]. PD patients had significantly higher GlcCer levels in the substantia nigra compared to age-matched controls. However, the level of ganglioside GM1a in the substantia nigra declined with age in both the human control subjects and PD patients (Table 3 and 4) [60]. In PD patients all the main brain gangliosides (GM1a, GD1a, GD1b and GT1b) were significantly reduced compared to control subjects (Table 4) [60]. A reduction in gangliosides was also seen in CSF and plasma from PD patients compared to age-matched controls (Table 4), as well as in prodromal RBD (rapid eye movement sleep behaviour disorder) patients [60].

These age-related GSL changes were also conserved in mice, with GCase reduction and GlcCer increase, and a reduction in gangliosides, with the notable exception of GM1a [76]. Interestingly, in the murine brain, GM1a increased with age, as opposed to decreasing in the human brain, perhaps due to a compensatory mechanism (Table 3 ) [76]. Although the mouse data is from whole brain homogenates and must be interpreted with caution, it may suggest an interesting difference between mouse and human brain GSL biochemistry. A similar bypass was seen in the engineered $\mathrm{Hexa}^{-/-}$Tay-Sachs disease mouse [77]. The mouse as a model organism only develops a Tay-Sachs disease phenotype when the sialidase enzyme neuraminidase 3 (encoded by Neu3), which is thought to facilitate GM2 degradation through this bypass pathway, is knocked out, in combination with the primary Hexa gene [77]. Neuraminidase activity normally increases with age in the mouse and combined with HEXB activity can bypass the Tay-Sachs disease catabolic defect allowing the mouse to escape disease $[76,77]$.

\section{The relevance of GM1a to PD}

The complex ganglioside GM1a is of known importance in PD (reviewed in detail in [78]). GM1a levels increase during neuronal development, regulating calcium flux across the nuclear membrane [79] and interacting with proteins such as NGF (nerve growth factor), BDNF (brain-derived neurotrophic factor) and GDNF (glial-derived neurotrophic factor) via Trk tyrosine kinases promoting signalling [80]. BDNF signalling is involved in neuritogenesis, differentiation and survival [81]. Decreased BDNF is seen in serum and brain in $\mathrm{PD}$ and correlates with degeneration of dopaminergic neurons [82, 83]. Failure of GDNF signalling has been associated with dopaminergic cell loss in PD and GDNF has been investigated as a PD therapy, though it was able to rescue neurons only in the early stages of degeneration in rats and has limited success in human PD patients [84-86]. Huebecker et al. found that GM1a decreases with age in the substantia nigra and putamen in humans, and this occurs to an even greater degree in the PD brain [60]. A reduction in GM1a levels was previously noted in the substantia nigra and occipital cortex from PD patients, and specifically in the nigral dopaminergic neurons compared to age-matched controls [87, 88]. A significant decrease in both B3GALT4 (GM1 synthase) and ST3GAL2 (sialyltransferase-4) gene

Table 2 Enzyme activity changes in PD vs age matched controls [60]. Arrows indicate significance $p=<0.05$

\begin{tabular}{|c|c|c|c|c|c|c|}
\hline & glucocerebrosidase (GBA) & $\beta$-glucosidase (GBA2) & $\alpha$-galactosidase & $\beta$-hexosaminidase & $\beta$-galactosidase & $\overline{\text { neuraminidase }}$ \\
\hline Substantia Nigra & $\downarrow$ & $\downarrow$ & $\downarrow$ & $\downarrow$ & $\downarrow$ & $\downarrow$ \\
\hline
\end{tabular}


Table 3 GSLs level changes in ageing mouse [76] and human brain [60]. Arrows indicate significance $p=<0.05$

\begin{tabular}{|c|c|c|c|c|c|c|c|c|c|}
\hline & Total GSLs & $\begin{array}{l}\text { Total } \\
\text { gangliosides }\end{array}$ & GlcCer & GlcSph & LacCer & GM1a & GD1a & GD1b & GT1b \\
\hline Mouse & $\uparrow$ & & $\uparrow$ & $\uparrow$ & $\uparrow$ & $\uparrow$ & $\downarrow$ & $\downarrow$ & $\downarrow$ \\
\hline $\begin{array}{l}\text { Human } \\
\text { Controls } \\
\text { Substantia } \\
\text { Nigra }\end{array}$ & - & - & - & - & - & $\downarrow$ & - & - & - \\
\hline $\begin{array}{l}\text { Human PD } \\
\text { Substantia } \\
\text { Nigra }\end{array}$ & $\uparrow$ & $\downarrow$ & $\uparrow$ & - & - & $\downarrow$ & - & $\downarrow$ & - \\
\hline
\end{tabular}

expression, resulting in reduced GM1a expression, was shown in residual neuromelanin-containing cells in the substantia nigra of PD patients compared to age-matched controls [89].

Several in vitro cell and mouse models have implicated GM1a as important player in PD pathology. Inhibition of GM1 synthase in neurons in vitro using siRNA decreased GM1a levels and increased cell vulnerability to the neurotoxin MPTP [90]. B4galnt ${ }^{ \pm}$mice have reduced GM1a and substantia nigra neuropathology as well as gastro, cardiac and cognitive symptoms [87, 88]. Treatment of B4galnt $\mathbf{1}^{ \pm}$ mice with GM1a led to decreased alpha-synuclein and rescued the motor deficits [88]. Surprisingly, treatment with only the oligosaccharide portion of GM1a resulted in complete rescue of the $B 4$ galnt $1^{ \pm}$mice, suggesting the oligosaccharide is the bioactive element responsible for neurotrophic function [91]. No differences in GM1a or gangliosides were seen in the brain, therefore the treatment did not alter the GSL pathway [91]. It should be noted that B $_{\text {galnt }}{ }^{ \pm}$ mice present with a reduction in all complex gangliosides in the brain, but GM1a is only slightly reduced, whereas GD1a is further reduced, and GD3 and GD1b are significantly increased [9] (see Fig. 2). A GD3 synthase (St8sial) (b-series) lentiviral shRNA KO mouse model demonstrated protection against MPTP-induced PD, had increased GM1a (and GD1b) in the brain, and reduced nigrostriatal damage, bradykinesia, and fine-motor-skill deficits [92]. One study which aimed to increase endogenous GM1a, injected Vibrio cholera sialidase in a rodent PD model (MPTP)[93]. Although sialidase administration did not demonstrate as much benefit good efficacy as systemic GM1a administration on all aspects of pathology, it did show similar efficacy in sparing of the DA neurons and as such may be a promising route [93]. In a rat alpha-synuclein model GM1a administration reduced alpha-synuclein aggregation, protected against loss of substantia nigra dopamine neurons and striatal dopamine levels, and furthermore, delayed start of GM1a administration was able to reverse behavioural deficits [94].

After numerous smaller studies on the use of GM1a (administered via subcutaneous injection) clinical trials were initiated and demonstrated clinical efficacy in PD patients [95, 96]. GM1a administration was shown to be safe and resulted in a slower rate of progression of PD symptoms [96]. These promising results warrant further research into GSLs, including the oligosaccharide moieties, as neuroprotective therapies.

\section{Relevance of other gangliosides to PD}

When discussing the mouse models used to investigate GM1a, such as B4galnt1 ${ }^{ \pm}$and St8sial ${ }^{-/-}$, it is important to understand that the GSL alterations are not confined only to GM1a. It is becoming apparent that the GSL landscape in the human brain is altered with ageing and in PD. In addition to reductions in GM1a; GD1a, GD1b and GT1b are also reduced in PD substantia nigra (Table 4) [60]. Another small study found a similar reduction in GD1a , GT1b, GD1b, and GM1a in the substantia nigra of PD patients, as well as an increase in GlcCer and sphingomyelin [97].

There is evidence that GD1a is also involved in neuronal development. GD1a injection into the striatum of MPTPtreated mice significantly increased striatal dopamine levels,

Table 4 GSLs level changes in PD vs age matched controls [60]. Arrows indicate significance $p=<0.05$

\begin{tabular}{llllllllllllllll}
\hline & Total GSLs & $\begin{array}{l}\text { Total } \\
\text { gangliosides }\end{array}$ & GlcCer & GlcSph & LacCer & GM1a & GD1a & GD1b & GT1b & GM3 & GM2 & GD3 & Gb3 & Gb4 \\
\hline Substantia Nigra & $\uparrow$ & $\downarrow$ & $\uparrow$ & $\uparrow$ & - & $\downarrow$ & $\downarrow$ & $\downarrow$ & $\downarrow$ & & \\
CSF & $\downarrow$ & $\downarrow$ & & & $\uparrow$ & - & $\downarrow$ & $\downarrow$ & $\downarrow$ & $\uparrow$ & $\downarrow$ & $\downarrow$ \\
Serum & & & - & & - & $\downarrow$ & $\downarrow$ & & & - & - & \\
\hline
\end{tabular}


to a greater extent than GM1a, in aged mice [98]. GD1a/ GT1b play a role in myelination and axon-myelin stability, via interaction with myelin-associated glycoproteins (MAGs) [99, 100]. GQ1b has neurotrophic actions such as increasing neurite outgrowth, cell proliferation, and longterm potentiation, by regulating BDNF [101]. The neuraminidase inhibitor DANA increased GQ1b/GT1a expression in neuronal culture and was shown to regulate glutamate release [102]. The addition of endogenous GQ1b was shown to ameliorate cognitive impairments via BDNF in another neurodegenerative disease, Alzheimer's (in a triple transgenic mouse model), and GQ1b increased BDNF expression more effectively than GM1a [103]. As well as a reduction of the complex brain gangliosides, GD3 is increased during both normal human ageing and in neurodegenerative disorders [104]. Interestingly, intranasal GD3 was shown to reduce alpha-synuclein in the A53T overexpressing mouse model in a similar fashion to GM1a [105]. However the addition of GM1a and GD3 had opposing effects on dopaminergic TH levels [105].

Neuraminidases (most likely neuraminidase 3 ) have the unique ability to re-model gangliosides at the plasma membrane meaning cells can adapt rapidly to stimuli and are not reliant solely on de novo biosynthesis. Neuraminidase activity actively regulates memory processing in rat hippocampus and enzymatic activity is increased by BDNF signalling [106]. Neuraminidase levels were also shown to decrease with age in mice and humans (substantia nigra), and therefore their ability to finely regulate the plasma membrane surface expression of GSLs in the brain may be restricted $[60,107]$. The age-related reduction in enzymes involved in GSL metabolism, including GCase and neuraminidases, likely accounts for these changes in GSL composition in the ageing brain and may be relevant to PD risk.

\section{GSLs and neurodegeneration}

The direct toxic effects of GlcCer and GlcSph remain elusive, particularly in GBA-linked PD. Although the author's studies found a clear increase in GlcCer and GlcSph levels in the substantia nigra of PD patients $[28,60]$, previous studies have found no accumulation in the PD brain [29]. In CBE treated mice, there was a direct correlation between the amount of CBE injected and levels of accumulation of GlcCer and GlcSph [108]. Disease pathology, indicated by altered levels of pathological markers, depended on both the levels of accumulated lipids and the time at which their accumulation began. Both GlcCer and GlcSph have been reported to specifically promote the formation of oligomeric alpha-synuclein and thus mediate neuropathology in GBA-associated PD [109]. However, when the hyperechogenic area of the substantia nigra, a prodromal PD marker, was measured in a large cohort of GBA mutation carriers $(\mathrm{n}=71)$ and patients with GD $(\mathrm{n}=145)$ it did not correlate with levels of GlcSph [31].

The mechanism by which GM1a exerts protection from neurodegeneration is still uncertain. It has been postulated that it is involved in the degradation of alpha-synuclein via enhanced autophagosomal activity [110]. It has also been shown that alpha-synuclein binds GM1a rich domains in synaptic vesicle fusion [111]. GM1a acts as a plasma membrane anchor for alpha-synuclein, which adopts a stable, alpha helical structure when bound, but in the absence of GM1a, starts to form fibrils [112].

Impaired GSL metabolism can also affect a plethora of downstream cellular processes. GSL accumulation, as well as preventing normal lysosomal degradation, affects fundamental processes such as mitochondrial respiration and autophagy [113]. The most commonly used PD model relies on the neurotoxin MPTP that selectively affects the dopaminergic neurons of the substantia nigra. MPTP has been shown to cause lysosomal dysfunction and its effects to be age dependent [114]. Lysosomal disruption causes alphasynuclein accumulation, and alpha-synuclein reciprocally causes lysosomal dysfunction.

GD3 is reported to be involved in autophagosomal biogenesis [113] and has been shown to mediate mitochondrial apoptosis in many cell types [115]. Gangliosides, in particular GD3, can also induce apoptosis in astrocytes [116]. However, in a mouse model of Gaucher disease the absence of apoptotic cell death and caspase activation despite the onset of overt neurodegeneration implicated necroptosis rather than apoptosis [117]. Levels of RIPK1 and RIPK3 were elevated both in microglia and neurons correlating with neuroinflammation and neuronal cell death and RIPK3 deficiency resulted in increased survival [117].

Membrane contact sites (MCS), between organelles, and between organelles and the PM, are essential for signalling and metabolite exchange, and are composed of discreet microdomains of tightly regulated lipids including GSLs [118]. Failure to digest or process the GSLs in lysosomes alters the lipid composition and functional properties of MCS. It has been demonstrated that failure to degrade GM1a led to redistribution of GM1a to the PM and ER, as seen in the LSD GM1 gangliosidosis. GM1a accumulation at mitochondria:ER MCSs caused $\mathrm{Ca}^{++}$dependent mitochondrial apoptosis [119] a possible cause of neuronal cell death and neurodegeneration [118]. GBA-PD patient-derived dopaminergic neurons exhibit prolonged mitochondrial:lysosomal contacts, resulting in disrupted mitochondrial distribution and function [120]. This was recapitulated with endogenous GlcCer treatment, and GBAPD neuron tethering could be rescued by increasing GCase activity with a GCase modulator [120].

GSLs at the PM are tightly regulated in a cell-specific manner, and different cell types-neurons, astrocytes, and 
microglia—appear differentially affected by changes in GSLs [23]. Dopaminergic neurons of the substantia nigra appear to be particularly susceptible in PD and may reflect distinct GSL changes. Remodelling at the PM would likely disrupt neuronal PM interactions such as those of GM1a with BDNF, GDNF and NGF via Trk receptors [121], calcium channel signalling and synaptic transmission of dopamine and therefore negatively affect neuronal survival [78]. Interestingly, cell studies demonstrated that endogenous oligomeric GM1a administration was intercalated into the PM and did not enter the cell, confirming its neuroprotective action was at the PM [122]. The gangliosides play roles in neuronal homeostasis including myelination, axon formation, signalling and neurotransmitter release $[80,100,101,121,122]$. In the brain, GSLs are therefore not only involved in general lysosomal/ autophagic cell functions and mitochondrial function but also at the plasma membrane in neuronal signalling and survival, and therefore changes in GSL levels increase the risk for PD. Although GM1a is of importance in neuronal function, and administration of GM1a has shown modest effects in the human disease, the restoration of normal neuronal GSL levels and normal GSL metabolism potentially may be of even greater benefit.

\section{Conclusion}

The importance of altered GSL metabolism has become apparent in the study of normal ageing of the brain. Changes in the GSL 'landscape' with ageing (relative amounts and distribution) represents a risk factor for PD beyond $G B A$ and may explain why so many LSD-causing gene variants are found over-represented in the heterozygous state in sporadic PD [46]. The precise mechanisms that underpin this increased risk are currently under investigation and may be multifactorial. GSLs are involved in mediating a plethora of cellular functions such as trafficking, autophagy, and signalling. Their biosynthesis and expression are highly cell type specific. As evidenced by the LSDs, the CNS is particularly vulnerable to lysosomal and GSL perturbations. In neurodegenerative diseases such as PD the brain shows age-related regional patterns of degeneration. Normal age-related GSL changes, possibly due to alterations in GSL metabolising enzyme activity, exacerbated by any one of a number of genetic or environmental modifiers, could lead to neurodegeneration and therefore PD. With greater knowledge of these risk factors, it may be possible to identify patients at greater risk of PD and target novel clinical intervention points, some of which may relate to restoring GSL homeostasis.
Abbreviations BDNF: Brain-derived neurotrophic factor; CBD: Corticobasal degeneration; CERS: Ceramide synthases; CNS: Central nervous system; CBE: Conduritol B epoxide; GALC: Galactocerebrosidase; GCase: Glucocerebrosidase; GDNF: Glial-derived neurotrophic factor; GlcCer: GlucosylCeramide; GlcSph: GlucosylSphingosine; GSL: Glycosphingolipid; LSD: Lysosomal Storage Disease; MCS: Membrane contact sites; NCL: Neuronal ceroid lipofuscinosis; NGF: Nerve growth factor; NPC: Niemann-Pick Disease; PD: Parkinson's disease; PGRN: Progranulin; PSP: Progressive supranuclear palsy

Acknowledgements MEFS was funded by NPSuisse, Niemann-PickUK and The Niemann-Pick Research Fund and Michael J. Fox Foundation for Parkinson's Research (MJFF). DAP was funded by Aligning Science Across Parkinson's [ASAP0478] through the Michael J. Fox Foundation for Parkinson's Research (MJFF). MH was funded by Parkinson's UK (grant H-1501). PH and OI were funded by NIH/NIA R01AG060195, DoD W81XWH2010368, DoD W81XWH2010371, the Orchard Foundation, the Harold and Ronna Cooper Family and the Consolidated Anti-Aging Foundation. FP was funded by The Royal Societyand The Wellcome Trust.

Funding No funding was received to assist with the preparation of this manuscript.

Data availability Not applicable.

Code availability Not applicable.

\section{Declarations}

Ethics approval Not applicable.

Consent to participate Not applicable.

Consent for publication Not applicable.

Conflicts of interest The authors have no relevant financial or nonfinancial interests to disclose.

Open Access This article is licensed under a Creative Commons Attribution 4.0 International License, which permits use, sharing, adaptation, distribution and reproduction in any medium or format, as long as you give appropriate credit to the original author(s) and the source, provide a link to the Creative Commons licence, and indicate if changes were made. The images or other third party material in this article are included in the article's Creative Commons licence, unless indicated otherwise in a credit line to the material. If material is not included in the article's Creative Commons licence and your intended use is not permitted by statutory regulation or exceeds the permitted use, you will need to obtain permission directly from the copyright holder. To view a copy of this licence, visit http://creativecommons.org/licenses/by/4.0/.

\section{References}

1. Gault, C.R.O.L., Hannun, Y.A.: An overview of sphingolipid metabolism: from synthesis to breakdown. Adv Exp Med Biol. 688, 1-23 (2010). https://doi.org/10.1007/ 978-1-4419-6741-1_1 
2. Tidhar, R., Ben-Dor, S., Wang, E., Kelly, S., Merrill, A.H., Jr., Futerman, A.H.: Acyl chain specificity of ceramide synthases is determined within a region of 150 residues in the Tram-LagCLN8 (TLC) domain. J. Biol. Chem. 287(5), 3197-3206 (2012). https://doi.org/10.1074/jbc.M111.280271

3. Levy, M., Futerman, A.H.: Mammalian ceramide synthases. IUBMB life 62(5), 347-356 (2010). https://doi.org/10.1002/iub.319

4. D’Angelo, G., Uemura, T., Chuang, C.C., Polishchuk, E., Santoro, M., Ohvo-Rekila, H., Sato, T., Di Tullio, G., Varriale, A., D’Auria, S., Daniele, T., Capuani, F., Johannes, L., Mattjus, P., Monti, M., Pucci, P., Williams, R.L., Burke, J.E., Platt, F.M., Harada, A., De Matteis, M.A.: Vesicular and non-vesicular transport feed distinct glycosylation pathways in the Golgi. Nature 501(7465), 116-120 (2013). https://doi.org/10.1038/nature12423

5. Russo, D., Capolupo, L., Loomba, J.S., Sticco, L., D'Angelo, G.: Glycosphingolipid metabolism in cell fate specification. J Cell Sci 131(24) (2018). https://doi.org/10.1242/jcs.219204

6. Platt, F.M.: Sphingolipid lysosomal storage disorders. Nature 510(7503), 68-75 (2014). https://doi.org/10.1038/nature13476

7. Schnaar, R.L.: Gangliosides of the Vertebrate Nervous System. J Mol Biol 428(16), 3325-3336 (2016). https://doi.org/10.1016/j. jmb.2016.05.020

8. Yamashita, T., Wada, R., Sasaki, T., Deng, C., Bierfreund, U., Sandhoff, K., Proia, R.L.: A vital role for glycosphingolipid synthesis during development and differentiation. Proc Natl Acad Sci U S A 96(16), 9142-9147 (1999)

9. Bhuiyan, R.H., Ohmi, Y., Ohkawa, Y., Zhang, P., Takano, M., Hashimoto, N., Okajima, T., Furukawa, K., Furukawa, K.: Loss of Enzyme Activity in Mutated B4GALNT1 Gene Products in Patients with Hereditary Spastic Paraplegia Results in Relatively Mild Neurological Disorders: Similarity with Phenotypes of B4galnt1 Knockout Mice. Neuroscience 397, 94-106 (2019). https://doi.org/10.1016/j.neuroscience.2018.11.034

10. Simpson, M.A., Cross, H., Proukakis, C., Priestman, D.A., Neville, D.C., Reinkensmeier, G., Wang, H., Wiznitzer, M., Gurtz, K., Verganelaki, A., Pryde, A., Patton, M.A., Dwek, R.A., Butters, T.D., Platt, F.M., Crosby, A.H.: Infantile-onset symptomatic epilepsy syndrome caused by a homozygous loss-of-function mutation of GM3 synthase. Nat Genet 36(11), 1225-1229 (2004). https://doi.org/10.1038/ng1460

11. O Neudorfer, N.G., Elstein, D., Abrahamov, A., Turezkite, T., Aghai, E., Reches, A., Bembi, B., Zimran, A.: Occurrence of Parkinson's syndrome in type I Gaucher disease. QJM 89(9), 691-694 (1996). https://doi.org/10.1093/qjmed/89.9.691

12. Sidransky, E., Nalls, M.A., Aasly, J.O., Aharon-Peretz, J., Annesi, G., Barbosa, E.R., Bar-Shira, A., Berg, D., Bras, J., Brice, A., Chen, C.M., Clark, L.N., Condroyer, C., De Marco, E.V., Durr, A., Eblan, M.J., Fahn, S., Farrer, M.J., Fung, H.C., Gan-Or, Z., Gasser, T., Gershoni-Baruch, R., Giladi, N., Griffith, A., Gurevich, T., Januario, C., Kropp, P., Lang, A.E., Lee-Chen, G.J., Lesage, S., Marder, K., Mata, I.F., Mirelman, A., Mitsui, J., Mizuta, I., Nicoletti, G., Oliveira, C., Ottman, R., OrrUrtreger, A., Pereira, L.V., Quattrone, A., Rogaeva, E., Rolfs, A., Rosenbaum, H., Rozenberg, R., Samii, A., Samaddar, T., Schulte, C., Sharma, M., Singleton, A., Spitz, M., Tan, E.K., Tayebi, N., Toda, T., Troiano, A.R., Tsuji, S., Wittstock, M., Wolfsberg, T.G., Wu, Y.R., Zabetian, C.P., Zhao, Y., Ziegler, S.G.: Multicenter analysis of glucocerebrosidase mutations in Parkinson's disease. N Engl J Med 361(17), 1651-1661 (2009). https://doi.org/10.1056/NEJMoa0901281

13. Anheim M, E.S., Lesage A, Durr C, Condroyer C, Viallet F, Pollak B, Bonaiti-Pellie C, Brice A: Penetrance of Parkinson disease in glucocerebrosidase gene mutation carriers. Neurology 78(6), 417-420 (2012). https://doi.org/10.1212/WNL. 0b013e $318245 f 476$
14. Malek, N., Weil, R.S., Bresner, C., Lawton, M.A., Grosset, K.A., Tan, M., Bajaj, N., Barker, R.A., Burn, D.J., Foltynie, T., Hardy, J., Wood, N.W., Ben-Shlomo, Y., Williams, N.W., Grosset, D.G., Morris, H.R., consortium, P.R.c.: Features of GBA-associated Parkinson's disease at presentation in the UK Tracking Parkinson's study. J Neurol Neurosurg Psychiatry 89(7), 702-709 (2018). https://doi.org/10.1136/jnnp-2017-317348

15. Mehta, A.: Epidemiology and natural history of Gaucher's disease. Eur J Intern Med 17(Suppl), S2-5 (2006). https://doi.org/ 10.1016/j.ejim.2006.07.005

16. Fernandes, H.J., Hartfield, E.M., Christian, H.C., Emmanoulidou, E., Zheng, Y., Booth, H., Bogetofte, H., Lang, C., Ryan, B.J., Sardi, S.P., Badger, J., Vowles, J., Evetts, S., Tofaris, G.K., Vekrellis, K., Talbot, K., Hu, M.T., James, W., Cowley, S.A., Wade-Martins, R.: ER Stress and Autophagic Perturbations Lead to Elevated Extracellular alpha-Synuclein in GBA-N370S Parkinson's iPSC-Derived Dopamine Neurons. Stem Cell Reports 6(3), 342-356 (2016). https://doi.org/10.1016/j.stemcr.2016.01.013

17. Goker-Alpan, O., Stubblefield, B.K., Giasson, B.I., Sidransky, E.: Glucocerebrosidase is present in alpha-synuclein inclusions in Lewy body disorders. Acta Neuropathol 120(5), 641-649 (2010). https://doi.org/10.1007/s00401-010-0741-7

18. Duran, R., Mencacci, N.E., Angeli, A.V., Shoai, M., Deas, E., Houlden, H., Mehta, A., Hughes, D., Cox, T.M., Deegan, P., Schapira, A.H., Lees, A.J., Limousin, P., Jarman, P.R., Bhatia, K.P., Wood, N.W., Hardy, J., Foltynie, T.: The glucocerobrosidase E326K variant predisposes to Parkinson's disease, but does not cause Gaucher's disease. Mov Disord 28(2), 232-236 (2013). https://doi.org/10.1002/mds.25248

19. Mazzulli, J.R., Xu, Y.H., Sun, Y., Knight, A.L., McLean, P.J., Caldwell, G.A., Sidransky, E., Grabowski, G.A., Krainc, D.: Gaucher disease glucocerebrosidase and alpha-synuclein form a bidirectional pathogenic loop in synucleinopathies. Cell 146(1), 37-52 (2011). https://doi.org/10.1016/j.cell.2011.06.001

20. Yap, T.L., Velayati, A., Sidransky, E., Lee, J.C.: Membranebound alpha-synuclein interacts with glucocerebrosidase and inhibits enzyme activity. Mol Genet Metab 108(1), 56-64 (2013). https://doi.org/10.1016/j.ymgme.2012.11.010

21. Barber, M.S., Muller, H.M., Gilbert, R.G., Baldwin, A.J.: Glucocerebrosidase rescues alpha-synuclein from amyloid formation. Biophys. J . (2018). https://doi.org/10.1101/363986

22. Rocha, E.M., Smith, G.A., Park, E., Cao, H., Graham, A.R., Brown, E., McLean, J.R., Hayes, M.A., Beagan, J., Izen, S.C., Perez-Torres, E., Hallett, P.J., Isacson, O.: Sustained Systemic Glucocerebrosidase Inhibition Induces Brain alpha-Synuclein Aggregation, Microglia and Complement C1q Activation in Mice. Antioxid Redox Signal 23(6), 550-564 (2015). https:// doi.org/10.1089/ars.2015.6307

23. Brekk, O.R., Honey, J.R., Lee, S., Hallett, P.J., Isacson, O.: Cell type-specific lipid storage changes in Parkinson's disease patient brains are recapitulated by experimental glycolipid disturbance. Proc Natl Acad Sci U S A 117(44), 27646-27654 (2020). https:// doi.org/10.1073/pnas.2003021117

24. Henderson, M.X., Sedor, S., McGeary, I., Cornblath, E.J., Peng, C., Riddle, D.M., Li, H.L., Zhang, B., Brown, H.J., Olufemi, M.F., Bassett, D.S., Trojanowski, J.Q., Lee, V.M.Y.: Glucocerebrosidase Activity Modulates Neuronal Susceptibility to Pathological alpha-Synuclein Insult. Neuron 105(5), 822-836 e827 (2020). https://doi.org/10.1016/j.neuron.2019.12.004

25. Rocha, E.M., Smith, G.A., Park, E., Cao, H., Brown, E., Hayes, M.A., Beagan, J., McLean, J.R., Izen, S.C., Perez-Torres, E., Hallett, P.J., Isacson, O.: Glucocerebrosidase gene therapy prevents alphasynucleinopathy of midbrain dopamine neurons. Neurobiol Dis 82, 495-503 (2015). https://doi.org/10.1016/j.nbd.2015.09.009 
26. Sardi, S.P., Clarke, J., Viel, C., Chan, M., Tamsett, T.J., Treleaven, C.M., Bu, J., Sweet, L., Passini, M.A., Dodge, J.C., Yu, W.H., Sidman, R.L., Cheng, S.H., Shihabuddin, L.S.: Augmenting CNS glucocerebrosidase activity as a therapeutic strategy for parkinsonism and other Gaucher-related synucleinopathies. Proc Natl Acad Sci U S A 110(9), 3537-3542 (2013). https://doi.org/10. 1073/pnas.1220464110

27. Gegg, M.E., Burke, D., Heales, S.J., Cooper, J.M., Hardy, J., Wood, N.W., Schapira, A.H.: Glucocerebrosidase deficiency in substantia nigra of parkinson disease brains. Ann Neurol 72(3), 455-463 (2012). https://doi.org/10.1002/ana.23614

28. Rocha, E.M., Smith, G.A., Park, E., Cao, H., Brown, E., Hallett, P., Isacson, O.: Progressive decline of glucocerebrosidase in aging and Parkinson's disease. Ann Clin Transl Neurol 2(4), 433-438 (2015). https://doi.org/10.1002/acn3.177

29. Gegg, M.E., Sweet, L., Wang, B.H., Shihabuddin, L.S., Sardi, S.P., Schapira, A.H.: No evidence for substrate accumulation in Parkinson brains with GBA mutations. Mov Disord 30(8), 1085-1089 (2015). https://doi.org/10.1002/mds.26278

30. Lerche, S., Schulte, C., Wurster, I., Machetanz, G., Roeben, B., Zimmermann, M., Deuschle, C., Hauser, A.K., Bohringer, J., Krageloh-Mann, I., Waniek, K., Lachmann, I., Petterson, X.T., Chiang, R., Park, H., Wang, B., Liepelt-Scarfone, I., Maetzler, W., Galasko, D., Scherzer, C.R., Gasser, T., Mielke, M.M., Hutten, S.J., Mollenhauer, B., Sardi, S.P., Berg, D., Brockmann, K.: The Mutation Matters: CSF Profiles of GCase, Sphingolipids, alphaSynuclein in PDGBA. Mov Disord (2021). https://doi.org/10. $1002 / \mathrm{mds} .28472$

31. Arkadir, D., Dinur, T., Becker Cohen, M., Revel-Vilk, S., Tiomkin, M., Bruggemann, N., Cozma, C., Rolfs, A., Zimran, A.: Prodromal substantia nigra sonography undermines suggested association between substrate accumulation and the risk for GBA-related Parkinson's disease. Eur J Neurol 26(7), 1013-1018 (2019). https:// doi.org/10.1111/ene.13927

32. Ziv Gan-Or, I.A.: Laura L Kilarski, Anat Bar-Shira, Mali Gana-Weisz, Anat Mirelman, Karen Marder, Susan Bressman, Nir Giladi, Avi Orr-Urtreger: Differential effects of severe vs mild GBA mutations on Parkinson disease. Neurology 84(9), 880-887 (2015). https://doi. org/10.1212/WNL.0000000000001315

33. Arkadir, D., Dinur, T., Mullin, S., Mehta, A., Baris, H.N., Alcalay, R.N., Zimran, A.: Trio approach reveals higher risk of PD in carriers of severe vs. mild GBA mutations. Blood Cells Mol Dis $\mathbf{6 8}$, 115-116 (2018). https://doi.org/10.1016/j.bcmd.2016.11.007

34. Lerche, S., Wurster, I., Roeben, B., Zimmermann, M., Riebenbauer, B., Deuschle, C., Hauser, A.K., Schulte, C., Berg, D., Maetzler, W., Waniek, K., Lachmann, I., Liepelt-Scarfone, I., Gasser, T., Brockmann, K.: Parkinson's Disease: Glucocerebrosidase 1 Mutation Severity Is Associated with CSF Alpha-Synuclein Profiles. Mov Disord 35(3), 495-499 (2020). https://doi.org/10. 1002/mds.27884

35. Blauwendraat, C., Reed, X., Krohn, L., Heilbron, K., BandresCiga, S., Tan, M., Gibbs, J.R., Hernandez, D.G., Kumaran, R., Langston, R., Bonet-Ponce, L., Alcalay, R.N., Hassin-Baer, S., Greenbaum, L., Iwaki, H., Leonard, H.L., Grenn, F.P., Ruskey, J.A., Sabir, M., Ahmed, S., Makarious, M.B., Pihlstrom, L., Toft, M., van Hilten, J.J., Marinus, J., Schulte, C., Brockmann, K., Sharma, M., Siitonen, A., Majamaa, K., Eerola-Rautio, J., Tienari, P.J., andMe Research, T., Pantelyat, A., Hillis, A.E., Dawson, T.M., Rosenthal, L.S., Albert, M.S., Resnick, S.M., Ferrucci, L., Morris, C.M., Pletnikova, O., Troncoso, J., Grosset, D., Lesage, S., Corvol, J.C., Brice, A., Noyce, A.J., Masliah, E., Wood, N., Hardy, J., Shulman, L.M., Jankovic, J., Shulman, J.M., Heutink, P., Gasser, T., Cannon, P., Scholz, S.W., Morris, H., Cookson, M.R., Nalls, M.A., Gan-Or, Z., Singleton, A.B.: Genetic modifiers of risk and age at onset in GBA associated Parkinson's disease and Lewy body dementia. Brain 143(1), 234-248 (2020). https:// doi.org/10.1093/brain/awz350

36. Klein, A.D., Ferreira, N.-S., Ben-Dor, S., Duan, J., Hardy, J., Cox, T.M., Merrill, A.H., Futerman, A.H.: Identification of Modifier Genes in a Mouse Model of Gaucher Disease. Cell Rep. 16(10), 2546-2553 (2016). https://doi.org/10.1016/j.celrep.2016.07.085

37. Schierding, W., Farrow, S., Fadason, T., Graham, O.E.E., Pitcher, T.L., Qubisi, S., Davidson, A.J., Perry, J.K., Anderson, T.J., Kennedy, M.A., Cooper, A., O'Sullivan, J.M.: Common Variants Coregulate Expression of GBA and Modifier Genes to Delay Parkinson's Disease Onset. Mov Disord 35(8), 1346-1356 (2020). https://doi.org/ $10.1002 /$ mds. 28144

38. Do, C.B., Tung, J.Y., Dorfman, E., Kiefer, A.K., Drabant, E.M., Francke, U., Mountain, J.L., Goldman, S.M., Tanner, C.M., Langston, J.W., Wojcicki, A., Eriksson, N.: Web-based genomewide association study identifies two novel loci and a substantial genetic component for Parkinson's disease. PLoS Genet 7(6), e1002141 (2011). https://doi.org/10.1371/journal.pgen.1002141

39. Alcalay, R.N., Levy, O.A., Wolf, P., Oliva, P., Zhang, X.K., Waters, C.H., Fahn, S., Kang, U., Liong, C., Ford, B., Mazzoni, P., Kuo, S., Johnson, A., Xiong, L., Rouleau, G.A., Chung, W., Marder, K.S., Gan-Or, Z.: SCARB2 variants and glucocerebrosidase activity in Parkinson's disease. NPJ Parkinsons Dis 2 (2016). https://doi.org/ 10.1038/npjparkd.2016.4

40. Thomas, R., Moloney, E.B., Macbain, Z.K., Hallett, P.J., Isacson, O.: Fibroblasts from idiopathic Parkinson's disease exhibit deficiency of lysosomal glucocerebrosidase activity associated with reduced levels of the trafficking receptor LIMP2. Mol Brain 14(1), 16 (2021). https://doi.org/10.1186/s13041-020-00712-3

41. Martin, S., Smolders, S., Van den Haute, C., Heeman, B., van Veen, S., Crosiers, D., Beletchi, I., Verstraeten, A., Gossye, H., Gelders, G., Pals, P., Hamouda, N.N., Engelborghs, S., Martin, J.J., Eggermont, J., De Deyn, P.P., Cras, P., Baekelandt, V., Vangheluwe, P., Van Broeckhoven, C., consortium, B.: Mutated ATP10B increases Parkinson's disease risk by compromising lysosomal glucosylceramide export. Acta Neuropathol 139(6), 1001-1024 (2020). https://doi. org/10.1007/s00401-020-02145-7

42. Baker, M., Mackenzie, I.R., Pickering-Brown, S.M., Gass, J., Rademakers, R., Lindholm, C., Snowden, J., Adamson, J., Sadovnick, A.D., Rollinson, S., Cannon, A., Dwosh, E., Neary, D., Melquist, S., Richardson, A., Dickson, D., Berger, Z., Eriksen, J., Robinson, T., Zehr, C., Dickey, C.A., Crook, R., McGowan, E., Mann, D., Boeve, B., Feldman, H., Hutton, M.: Mutations in progranulin cause tau-negative frontotemporal dementia linked to chromosome 17. Nature 442(7105), 916-919 (2006). https://doi.org/10.1038/nature05016

43. Cruts, M., Gijselinck, I., van der Zee, J., Engelborghs, S., Wils, H., Pirici, D., Rademakers, R., Vandenberghe, R., Dermaut, B., Martin, J.J., van Duijn, C., Peeters, K., Sciot, R., Santens, P., De Pooter, T., Mattheijssens, M., Van den Broeck, M., Cuijt, I., Vennekens, K., De Deyn, P.P., Kumar-Singh, S., Van Broeckhoven, C.: Null mutations in progranulin cause ubiquitin-positive frontotemporal dementia linked to chromosome 17q21. Nature 442(7105), 920-924 (2006). https://doi.org/10.1038/nature05017

44. Yao, Y.N., Wang, M.D., Tang, X.C., Wu, B., Sun, H.M.: Reduced plasma progranulin levels are associated with the severity of Parkinson's disease. Neurosci Lett 725, 134873 (2020). https://doi. org/10.1016/j.neulet.2020.134873

45. Zhou, X., Paushter, D.H., Pagan, M.D., Kim, D., Nunez Santos, M., Lieberman, R.L., Overkleeft, H.S., Sun, Y., Smolka, M.B., $\mathrm{Hu}, \mathrm{F}$.: Progranulin deficiency leads to reduced glucocerebrosidase activity. PLoS One 14(7), e0212382 (2019). https://doi.org/ 10.1371/journal.pone.0212382

46. Robak, L.A., Jansen, I.E., van Rooij, J., Uitterlinden, A.G., Kraaij, R., Jankovic, J., International Parkinson's Disease 
Genomics, C., Heutink, P., Shulman, J.M.: Excessive burden of lysosomal storage disorder gene variants in Parkinson's disease. Brain 140(12), 3191-3203 (2017). doi:https://doi.org/10.1093/ brain/awx285

47. Cullen, V., Lindfors, M., Ng, J., Paetau, A., Swinton, E., Kolodziej, P., Boston, H., Saftig, P., Woulfe, J., Feany, M.B., Myllykangas, L., Schlossmacher, M.G., Tyynela, J.: Cathepsin D expression level affects alpha-synuclein processing, aggregation, and toxicity in vivo. Mol Brain 2, 5 (2009). https://doi.org/10. 1186/1756-6606-2-5

48. Boccuto, L., Aoki, K., Flanagan-Steet, H., Chen, C.F., Fan, X., Bartel, F., Petukh, M., Pittman, A., Saul, R., Chaubey, A., Alexov, E., Tiemeyer, M., Steet, R., Schwartz, C.E.: A mutation in a ganglioside biosynthetic enzyme, ST3GAL5, results in salt \& pepper syndrome, a neurocutaneous disorder with altered glycolipid and glycoprotein glycosylation. Hum Mol Genet 23(2), 418-433 (2014). https://doi.org/10.1093/hmg/ddt434

49. Clarke, J., Kayatekin, C., Viel, C., Shihabuddin, L., Sardi, S.P.: Murine Models of Lysosomal Storage Diseases Exhibit Differences in Brain Protein Aggregation and Neuroinflammation. Biomedicines 9(5) (2021). https://doi.org/10.3390/ biomedicines 9050446

50. Gago, M.F., Azevedo, O., Guimaraes, A., Teresa Vide, A., Lamas, N.J., Oliveira, T.G., Gaspar, P., Bicho, E., MiltenbergerMiltenyi, G., Ferreira, J., Sousa, N.: Parkinson's Disease and Fabry Disease: Clinical, Biochemical and Neuroimaging Analysis of Three Pedigrees. J Parkinsons Dis 10(1), 141-152 (2020). https://doi.org/10.3233/JPD-191704

51. Alcalay, R.N., Wolf, P., Levy, O.A., Kang, U.J., Waters, C., Fahn, S., Ford, B., Kuo, S.H., Vanegas, N., Shah, H., Liong, C., Narayan, S., Pauciulo, M.W., Nichols, W.C., Gan-Or, Z., Rouleau, G.A., Chung, W.K., Oliva, P., Keutzer, J., Marder, K., Zhang, X.K.: Alpha galactosidase A activity in Parkinson's disease. Neurobiol Dis 112, 85-90 (2018). https://doi.org/10.1016/j. nbd.2018.01.012

52. Nelson, M.P., Boutin, M., Tse, T.E., Lu, H., Haley, E.D., Ouyang, X., Zhang, J., Auray-Blais, C., Shacka, J.J.: The lysosomal enzyme alpha-Galactosidase A is deficient in Parkinson's disease brain in association with the pathologic accumulation of alpha-synuclein. Neurobiol Dis 110, 68-81 (2018). https://doi.org/10.1016/j.nbd. 2017.11.006

53. Smith, B.R., Santos, M.B., Marshall, M.S., Cantuti-Castelvetri, L., Lopez-Rosas, A., Li, G., van Breemen, R., Claycomb, K.I., Gallea, J.I., Celej, M.S., Crocker, S.J., Givogri, M.I., Bongarzone, E.R.: Neuronal inclusions of alpha-synuclein contribute to the pathogenesis of Krabbe disease. J Pathol 232(5), 509-521 (2014). https://doi.org/10.1002/path.4328

54. Abdelkarim, H., Marshall, M.S., Scesa, G., Smith, R.A., Rue, E., Marshall, J., Elackattu, V., Stoskute, M., Issa, Y., Santos, M., Nguyen, D., Hauck, Z., van Breemen, R., Celej, M.S., Gaponenko, V., Bongarzone, E.R.: alpha-Synuclein interacts directly but reversibly with psychosine: implications for alphasynucleinopathies. Sci Rep 8(1), 12462 (2018). https://doi.org/ 10.1038/s41598-018-30808-9

55. Marshall, M.S., Jakubauskas, B., Bogue, W., Stoskute, M., Hauck, Z., Rue, E., Nichols, M., DiAntonio, L.L., van Breemen, R.B., Kordower, J.H., Saavedra-Matiz, C.A., Bongarzone, E.R.: Analysis of age-related changes in psychosine metabolism in the human brain. PLoS One 13(2), e0193438 (2018). https://doi.org/ 10.1371/journal.pone. 0193438

56. Suzuki, K., Iseki, E., Togo, T., Yamaguchi, A., Katsuse, O., Katsuyama, K., Kanzaki, S., Shiozaki, K., Kawanishi, C., Yamashita, S., Tanaka, Y., Yamanaka, S., Hirayasu, Y.: Neuronal and glial accumulation of alpha- and beta-synucleins in human lipidoses. Acta Neuropathol 114(5), 481-489 (2007). https://doi.org/10.1007/s00401-007-0264-z
57. Cachon-Gonzalez, M.B., Wang, S.Z., Ziegler, R., Cheng, S.H., Cox, T.M.: Reversibility of neuropathology in Tay-Sachs-related diseases. Hum Mol Genet 23(3), 730-748 (2014). https://doi.org/ 10.1093/hmg/ddt459

58. Brekk, O.R., Korecka, J.A., Crapart, C.C., Huebecker, M., MacBain, Z.K., Rosenthal, S.A., Sena-Esteves, M., Priestman, D.A., Platt, F.M., Isacson, O., Hallett, P.J.: Upregulating betahexosaminidase activity in rodents prevents alpha-synuclein lipid associations and protects dopaminergic neurons from alphasynuclein-mediated neurotoxicity. Acta Neuropathol Commun 8(1), 127 (2020). https://doi.org/10.1186/s40478-020-01004-6

59. Lloyd-Evans, E., Morgan, A.J., He, X., Smith, D.A., ElliotSmith, E., Sillence, D.J., Churchill, G.C., Schuchman, E.H., Galione, A., Platt, F.M.: Niemann-Pick disease type C1 is a sphingosine storage disease that causes deregulation of lysosomal calcium. Nat Med 14(11), 1247-1255 (2008). https://doi.org/ 10.1038/nm.1876

60. Huebecker, M., Moloney, E.B., van der Spoel, A.C., Priestman, D.A., Isacson, O., Hallett, P.J., Platt, F.M.: Reduced sphingolipid hydrolase activities, substrate accumulation and ganglioside decline in Parkinson's disease. Mol Neurodegener 14(1), 40 (2019). https://doi.org/10.1186/s13024-019-0339-z

61. Kilpatrick, B.S., Magalhaes, J., Beavan, M.S., McNeill, A., Gegg, M.E., Cleeter, M.W., Bloor-Young, D., Churchill, G.C., Duchen, M.R., Schapira, A.H., Patel, S.: Endoplasmic reticulum and lysosomal $\mathrm{Ca}(2)(+)$ stores are remodelled in GBA1-linked Parkinson disease patient fibroblasts. Cell Calcium 59(1), 12-20 (2016). https://doi.org/10.1016/j.ceca.2015.11.002

62. Saito, Y., Suzuki, K., Hulette, C.M., Murayama, S.: Aberrant phosphorylation of alpha-synuclein in human Niemann-Pick type C1 disease. J Neuropathol Exp Neurol 63(4), 323-328 (2004). https://doi.org/10.1093/jnen/63.4.323

63. Chiba, Y., Komori, H., Takei, S., Hasegawa-Ishii, S., Kawamura, N., Adachi, K., Nanba, E., Hosokawa, M., Enokido, Y., Kouchi, Z., Yoshida, F., Shimada, A.: Niemann-Pick disease type C1 predominantly involving the frontotemporal region, with cortical and brainstem Lewy bodies: an autopsy case. Neuropathology 34(1), 49-57 (2014). https://doi.org/10.1111/neup.12047

64. Josephs, K.A., Matsumoto, J.Y., Lindor, N.M.: Heterozygous Niemann-Pick disease type $\mathrm{C}$ presenting with tremor. Neurology 63(11), 2189-2190 (2004). https://doi.org/10.1212/01.wnl. $0000145710.25588 .2 \mathrm{f}$

65. Kluenemann, H.H., Nutt, J.G., Davis, M.Y., Bird, T.D.: Parkinsonism syndrome in heterozygotes for Niemann-Pick C1. J Neurol Sci 335(1-2), 219-220 (2013). https://doi.org/10.1016/j.jns.2013.08.033

66. Schneider, S.A., Tahirovic, S., Hardy, J., Strupp, M., BremovaErtl, T.: Do heterozygous mutations of Niemann-Pick type C predispose to late-onset neurodegeneration: a review of the literature. J Neurol (2019). https://doi.org/10.1007/s00415-019-09621-5

67. Benussi, A., Cotelli, M.S., Cantoni, V., Bertasi, V., Turla, M., Dardis, A., Biasizzo, J., Manenti, R., Cotelli, M., Padovani, A., Borroni, B.: Clinical and neurophysiological characteristics of heterozygous NPC1 carriers. JIMD Rep 49(1), 80-88 (2019). https://doi.org/10.1002/jmd2.12059

68. Ouled Amar Bencheikh, B., Senkevich, K., Rudakou, U., Yu, E., Mufti, K., Ruskey, J.A., Asayesh, F., Laurent, S.B., Spiegelman, D., Fahn, S., Waters, C., Monchi, O., Dauvilliers, Y., Espay, A.J., Dupre, N., Greenbaum, L., Hassin-Baer, S., Rouleau, G.A., Alcalay, R.N., Fon, E.A., Gan-Or, Z.: Variants in the Niemann-Pick type C gene NPC1 are not associated with Parkinson's disease. Neurobiol Aging 93, 143 e141-143 e144 (2020). https://doi.org/10.1016/j. neurobiolaging.2020.03.021

69. Ziv Gan-Or, L.J.O., Anat Bar-Shira, Rachel Saunders-Pullman, Anat Mirelman, Ruth Kornreich, Mali Gana-Weisz, Deborah Raymond, Liron Rozenkrantz, Andres Deik, Tanya Gurevich, Susan J Gross, Nicole Schreiber-Agus, Nir Giladi, Susan B 
Bressman, Avi Orr-Urtreger: The p.L302P mutation in the lysosomal enzyme gene SMPD1 is a risk factor for Parkinson disease. Neurology 80(17), 1606-1610 (2013). https://doi.org/10.1212/ WNL.0b013e31828f180e

70. Alcalay, R.N., Mallett, V., Vanderperre, B., Tavassoly, O., Dauvilliers, Y., Wu, R.Y.J., Ruskey, J.A., Leblond, C.S., Ambalavanan, A., Laurent, S.B., Spiegelman, D., Dionne-Laporte, A., Liong, C., Levy, O.A., Fahn, S., Waters, C., Kuo, S.H., Chung, W.K., Ford, B., Marder, K.S., Kang, U.J., Hassin-Baer, S., Greenbaum, L., Trempe, J.F., Wolf, P., Oliva, P., Zhang, X.K., Clark, L.N., Langlois, M., Dion, P.A., Fon, E.A., Dupre, N., Rouleau, G.A., Gan-Or, Z.: SMPD1 mutations, activity, and alpha-synuclein accumulation in Parkinson's disease. Mov Disord 34(4), 526-535 (2019). https:// doi.org/10.1002/mds.27642

71. Van Kampen, J.M., Baranowski, D., Kay, D.G.: Progranulin gene delivery protects dopaminergic neurons in a mouse model of Parkinson's disease. PLoS One 9(5), e97032 (2014). https://doi. org/10.1371/journal.pone.0097032

72. Bras, J., Verloes, A., Schneider, S.A., Mole, S.E., Guerreiro, R.J.: Mutation of the parkinsonism gene ATP13A2 causes neuronal ceroid-lipofuscinosis. Hum Mol Genet 21(12), 2646-2650 (2012). https://doi.org/10.1093/hmg/dds089

73. Ramirez, A., Heimbach, A., Grundemann, J., Stiller, B., Hampshire, D., Cid, L.P., Goebel, I., Mubaidin, A.F., Wriekat, A.L., Roeper, J., Al-Din, A., Hillmer, A.M., Karsak, M., Liss, B., Woods, C.G., Behrens, M.I., Kubisch, C.: Hereditary parkinsonism with dementia is caused by mutations in ATP13A2, encoding a lysosomal type 5 P-type ATPase. Nat Genet 38(10), 1184-1191 (2006). https://doi. org/10.1038/ng1884

74. Ledesma, M.D., Martin, M.G., Dotti, C.G.: Lipid changes in the aged brain: effect on synaptic function and neuronal survival. Prog Lipid Res 51(1), 23-35 (2012). https://doi.org/10.1016/j. plipres.2011.11.004

75. Skowronska-Krawczyk, D., Budin, I.: Aging membranes: Unexplored functions for lipids in the lifespan of the central nervous system. Exp Gerontol 131, 110817 (2020). https://doi.org/10. 1016/j.exger.2019.110817

76. Hallett, P.J., Huebecker, M., Brekk, O.R., Moloney, E.B., Rocha, E.M., Priestman, D.A., Platt, F.M., Isacson, O.: Glycosphingolipid levels and glucocerebrosidase activity are altered in normal aging of the mouse brain. Neurobiol Aging 67, 189-200 (2018). https://doi.org/10.1016/j.neurobiolaging.2018.02.028

77. Seyrantepe, V., Demir, S.A., Timur, Z.K., Von Gerichten, J., Marsching, C., Erdemli, E., Oztas, E., Takahashi, K., Yamaguchi, K., Ates, N., Donmez Demir, B., Dalkara, T., Erich, K., Hopf, C., Sandhoff, R., Miyagi, T.: Murine Sialidase Neu3 facilitates GM2 degradation and bypass in mouse model of Tay-Sachs disease. Exp Neurol 299(Pt A), 26-41 (2018). https://doi.org/10. 1016/j.expneurol.2017.09.012

78. Chiricozzi, E., Lunghi, G., Di Biase, E., Fazzari, M., Sonnino, S., Mauri, L.: GM1 Ganglioside Is A Key Factor in Maintaining the Mammalian Neuronal Functions Avoiding Neurodegeneration. Int J Mol Sci 21(3) (2020). https://doi.org/10.3390/ijms21030868

79. Ledeen, R.W.W.G., Lu, Z.H., Kozireski-Chuback, D., Fang, Y.: The role of GM1 and other gangliosides in neuronal differentiation. Overview and new finding. Ann N Y Acad Sci 845, 161-175 (1998). https://doi.org/10.1111/j.1749-6632.1998.tb09669.x

80. Hadaczek, P., Wu, G., Sharma, N., Ciesielska, A., Bankiewicz, K., Davidow, A.L., Lu, Z.H., Forsayeth, J., Ledeen, R.W.: GDNF signaling implemented by GM1 ganglioside; failure in Parkinson's disease and GM1-deficient murine model. Exp Neurol 263, 177-189 (2015). https://doi.org/10.1016/j.expneurol.2014.10.010

81. Kowianski, P., Lietzau, G., Czuba, E., Waskow, M., Steliga, A., Morys, J.: BDNF: A Key Factor with Multipotent Impact on Brain Signaling and Synaptic Plasticity. Cell Mol Neurobiol 38(3), 579593 (2018). https://doi.org/10.1007/s10571-017-0510-4
82. Wang, Y., Liu, H., Zhang, B.S., Soares, J.C., Zhang, X.Y.: Low BDNF is associated with cognitive impairments in patients with Parkinson's disease. Parkinsonism Relat Disord 29, 66-71 (2016). https://doi.org/10.1016/j.parkreldis.2016.05.023

83. Howells, D.W., Porritt, M.J., Wong, J.Y., Batchelor, P.E., Kalnins, R., Hughes, A.J., Donnan, G.A.: Reduced BDNF mRNA expression in the Parkinson's disease substantia nigra. Exp Neurol 166(1), 127-135 (2000). https://doi.org/10.1006/exnr.2000.7483

84. Pascual, A.H.-F.M., Piruat, J.I., Pintado, C.O., Gómez-Díaz, R., López-Barneo, J.: Absolute Requirement of GDNF for Adult Catecholaminergic Neuron Survival. Nat Neuroscience 11(7), 755-761 (2008).

85. Gill, S.S., Patel, N.K., Hotton, G.R., O'Sullivan, K., McCarter, R., Bunnage, M., Brooks, D.J., Svendsen, C.N., Heywood, P.: Direct brain infusion of glial cell line-derived neurotrophic factor in Parkinson disease. Nat Med 9(5), 589-595 (2003). https://doi.org/10.1038/nm850

86. Quintino, L., Avallone, M., Brannstrom, E., Kavanagh, P., Lockowandt, M., Garcia Jareno, P., Breger, L.S., Lundberg, C.: GDNF-mediated rescue of the nigrostriatal system depends on the degree of degeneration. Gene Ther 26(1-2), 57-64 (2019). https://doi.org/10.1038/s41434-018-0049-0

87. Wu, G., Lu, Z.H., Kulkarni, N., Ledeen, R.W.: Deficiency of ganglioside GM1 correlates with Parkinson's disease in mice and humans. J Neurosci Res 90(10), 1997-2008 (2012). https:// doi.org/10.1002/jnr.23090

88. Wu, G., Lu, Z.H., Seo, J.H., Alselehdar, S.K., DeFrees, S., Ledeen, R.W.: Mice deficient in GM1 manifest both motor and non-motor symptoms of Parkinson's disease; successful treatment with synthetic GM1 ganglioside. Exp Neurol 329, 113284 (2020). https://doi.org/10.1016/j.expneurol.2020.113284

89. Schneider, J.S.: Altered expression of genes involved in ganglioside biosynthesis in substantia nigra neurons in Parkinson's disease. PLoS One 13(6), e0199189 (2018). https://doi.org/10. 1371/journal.pone.0199189

90. Verma, M., Schneider, J.S.: siRNA-mediated knockdown of B3GALT4 decreases GM1 ganglioside expression and enhances vulnerability for neurodegeneration. Mol Cell Neurosci 95, 25-30 (2019). https://doi.org/10.1016/j.mcn.2019.01.001

91. Chiricozzi, E., Mauri, L., Lunghi, G., Di Biase, E., Fazzari, M., Maggioni, M., Valsecchi, M., Prioni, S., Loberto, N., Pome, D.Y., Ciampa, M.G., Fato, P., Verlengia, G., Cattaneo, S., Assini, R., Wu, G., Alselehdar, S., Ledeen, R.W., Sonnino, S.: Parkinson's disease recovery by GM1 oligosaccharide treatment in the B4galnt1(+/-) mouse model. Sci Rep 9(1), 19330 (2019). https:// doi.org/10.1038/s41598-019-55885-2

92. Dhanushkodi, A., Xue, Y., Roguski, E.E., Ding, Y., Matta, S.G., Heck, D., Fan, G.H., McDonald, M.P.: Lentiviral-mediated knock-down of GD3 synthase protects against MPTP-induced motor deficits and neurodegeneration. Neurosci Lett 692, 53-63 (2019). https://doi.org/10.1016/j.neulet.2018.10.038

93. Schneider, J.S., Seyfried, T.N., Choi, H.S., Kidd, S.K.: Intraventricular Sialidase Administration Enhances GM1 Ganglioside Expression and Is Partially Neuroprotective in a Mouse Model of Parkinson's Disease. PLoS One 10(12), e0143351 (2015). https:// doi.org/10.1371/journal.pone.0143351

94. Schneider, J.S., Aras, R., Williams, C.K., Koprich, J.B., Brotchie, J.M., Singh, V.: GM1 Ganglioside Modifies alpha-Synuclein Toxicity and is Neuroprotective in a Rat alpha-Synuclein Model of Parkinson's Disease. Sci Rep 9(1), 8362 (2019). https://doi. org/10.1038/s41598-019-42847-x

95. Schneider, J.S., Sendek, S., Daskalakis, C., Cambi, F.: GM1 ganglioside in Parkinson's disease: Results of a five year open study. J Neurol Sci 292(1-2), 45-51 (2010). https://doi.org/10.1016/j. jns.2010.02.009 
96. Schneider, J.S., Gollomp, S.M., Sendek, S., Colcher, A., Cambi, F., Du, W.: A randomized, controlled, delayed start trial of GM1 ganglioside in treated Parkinson's disease patients. J Neurol Sci 324(1-2), 140-148 (2013). https://doi.org/10.1016/j.jns.2012.10.024

97. Seyfried, T.N., Choi, H., Chevalier, A., Hogan, D., Akgoc, Z., Schneider, J.S.: Sex-Related Abnormalities in Substantia Nigra Lipids in Parkinson's Disease. ASN Neuro 10, 1759091418781889 (2018). https://doi.org/10.1177/1759091418781889

98. Date, I.N.M.F., Felton, S.Y., Felten, D.L.: Stereotaxic injection of GD1a ganglioside induces limited recovery of striatal dopaminergic system in MPTP-treated aging mice. J Neurosci Res 28(4), 525-530 (1991). https://doi.org/10.1002/jnr.490280409

99. Yang, L.J.Z.C., Shaper, N.L., Kiso, M., Hasegawa, A., Shapiro, R.E., Schnaar, R.L.: Gangliosides are neuronal ligands for myelinassociated glycoprotein. Proc Natl Acad Sci U S A 93(2), 814-818 (1996). https://doi.org/10.1073/pnas.93.2.814

100. Schnaar, R.L.: Brain gangliosides in axon-myelin stability and axon regeneration. FEBS Lett 584(9), 1741-1747 (2010). https:// doi.org/10.1016/j.febslet.2009.10.011

101. Shin, M.K., Jung, W.R., Kim, H.G., Roh, S.E., Kwak, C.H., Kim, C.H., Kim, S.J., Kim, K.L.: The ganglioside GQ1b regulates BDNF expression via the NMDA receptor signaling pathway. Neuropharmacology 77, 414-421 (2014). https://doi.org/10. 1016/j.neuropharm.2013.10.022

102. Minami, A., Ishii, A., Shimba, S., Kano, T., Fujioka, E., Sai, S., Oshio, N., Ishibashi, S., Takahashi, T., Kurebayashi, Y., Kanazawa, H., Yuki, N., Otsubo, T., Ikeda, K., Suzuki, T.: Down-regulation of glutamate release from hippocampal neurons by sialidase. J Biochem 163(4), 273-280 (2018). https://doi.org/10.1093/jb/mvy003

103. Shin, M.K., Choi, M.S., Chae, H.J., Kim, J.W., Kim, H.G., Kim, K.L.: Ganglioside GQ1b ameliorates cognitive impairments in an Alzheimer's disease mouse model, and causes reduction of amyloid precursor protein. Sci Rep 9(1), 8512 (2019). https:// doi.org/10.1038/s41598-019-44739-6

104. Malisan, F.T.R.: GD3 in cellular ageing and apoptosis. Exp Gerontol. 37(10-11), 1273-1282 (2002). doi:https://doi.org/10.1016/ s0531-5565(02)00138-9

105. Itokazu, Y., Fuchigami, T., Morgan, J.C., Yu, R.K.: Intranasal infusion of GD3 and GM1 gangliosides down-regulates alphasynuclein and controls tyrosine hydroxylase gene in a PD model mouse. Mol Ther (2021). https://doi.org/10.1016/j.ymthe.2021. 06.005

106. Minami, A., Meguro, Y., Ishibashi, S., Ishii, A., Shiratori, M., Sai, S., Horii, Y., Shimizu, H., Fukumoto, H., Shimba, S., Taguchi, R., Takahashi, T., Otsubo, T., Ikeda, K., Suzuki, T.: Rapid regulation of sialidase activity in response to neural activity and sialic acid removal during memory processing in rat hippocampus. J Biol Chem 292(14), 5645-5654 (2017). https://doi.org/10.1074/jbc. M116.764357

107. Saito, M.H.H., Ito, M., Ando, S., Yu, R.: Age-dependent reduction in sialidase activity of nuclear membranes from mouse brain. Exp Gerontology 37(7), 937-941 (2002). https://doi.org/10.1016/ s0531-5565(02)00021-9

108. Vardi, A., Zigdon, H., Meshcheriakova, A., Klein, A.D., Yaacobi, C., Eilam, R., Kenwood, B.M., Rahim, A.A., Massaro, G., Merrill, A.H., Jr., Vitner, E.B., Futerman, A.H.: Delineating pathological pathways in a chemically induced mouse model of Gaucher disease. J Pathol 239(4), 496-509 (2016). https://doi.org/10.1002/ path.4751

109. Taguchi, Y.V., Liu, J., Ruan, J., Pacheco, J., Zhang, X., Abbasi, J., Keutzer, J., Mistry, P.K., Chandra, S.S.: Glucosylsphingosine Promotes alpha-Synuclein Pathology in Mutant GBA-Associated Parkinson's Disease. J Neurosci 37(40), 9617-9631 (2017). https:// doi.org/10.1523/JNEUROSCI.1525-17.2017

110. Guo, Y.L., Duan, W.J., Lu, D.H., Ma, X.H., Li, X.X., Li, Z., Bi, W., Kurihara, H., Liu, H.Z., Li, Y.F., He, R.R.:
Autophagy-dependent removal of alpha-synuclein: a novel mechanism of GM1 ganglioside neuroprotection against Parkinson's disease. Acta Pharmacol Sin 42(4), 518-528 (2021). https://doi. org/10.1038/s41401-020-0454-y

111. Kaur, U., Lee, J.C.: Unroofing site-specific alpha-synuclein-lipid interactions at the plasma membrane. Proc Natl Acad Sci U S A 117(32), 18977-18983 (2020). https://doi.org/10.1073/pnas. 2006291117

112. Martinez, Z.Z.M., Fink, A.L.: GM1 specifically interacts with alpha-synuclein and inhibits fibrillation. Biochemistry 46(7), 1868-1877 (2007). https://doi.org/10.1021/bi061749a

113. Matarrese, P., Garofalo, T., Manganelli, V., Gambardella, L., Marconi, M., Grasso, M., Tinari, A., Misasi, R., Malorni, W., Sorice, M.: Evidence for the involvement of GD3 ganglioside in autophagosome formation and maturation. Autophagy 10(5), 750-765 (2014). https://doi.org/10.4161/auto.27959

114. Filipov, N.M., Norwood, A.B., Sistrunk, S.C.: Strain-specific sensitivity to MPTP of C57BL/6 and BALB/c mice is age dependent. NeuroReport 20(7), 713-717 (2009). https://doi.org/ 10.1097/WNR.0b013e32832aa95b

115. De Maria, R., Lenti, L., Malisan, F., d'Agostino, F., Tomassini, B., Zeuner, A., Rippo, M.R., Testi, R.: Requirement for GD3 Ganglioside in CD95- and Ceramide-Induced Apoptosis. Science 277(5332), 1652-1655 (1997). https://doi.org/10.1126/science. 277.5332 .1652

116. Hwang, J., Lee, S., Lee, J.T., Kwon, T.K., Kim, D.R., Kim, H., Park, H.C., Suk, K.: Gangliosides induce autophagic cell death in astrocytes. Br J Pharmacol 159(3), 586-603 (2010). https:// doi.org/10.1111/j.1476-5381.2009.00563.x

117. Vitner, E.B., Salomon, R., Farfel-Becker, T., Meshcheriakova, A., Ali, M., Klein, A.D., Platt, F.M., Cox, T.M., Futerman, A.H.: RIPK3 as a potential therapeutic target for Gaucher's disease. Nat Med 20(2), 204-208 (2014). https://doi.org/10.1038/nm.3449

118. Annunziata, I., Sano, R., d'Azzo, A.: Mitochondria-associated ER membranes (MAMs) and lysosomal storage diseases. Cell Death Dis 9(3), 328 (2018). https://doi.org/10.1038/s41419-017-0025-4

119. Sano, R., Annunziata, I., Patterson, A., Moshiach, S., Gomero, E., Opferman, J., Forte, M., d'Azzo, A.: GM1-ganglioside accumulation at the mitochondria-associated ER membranes links ER stress to $\mathrm{Ca}(2+)$-dependent mitochondrial apoptosis. Mol Cell 36(3), 500-511 (2009). https://doi.org/10.1016/j.molcel.2009. 10.021

120. Kim, S., Wong, Y.C., Gao, F., Krainc, D.: Dysregulation of mitochondria-lysosome contacts by GBA1 dysfunction in dopaminergic neuronal models of Parkinson's disease. Nat Commun 12(1), 1807 (2021). https://doi.org/10.1038/s41467-021-22113-3

121. Mutoh, T.T.A., Miyadai, T., Hamaguchi, M., Fujiki, N.: Ganglioside GM1 binds to the Trk protein and regulates receptor function. Proc Natl Acad Sci U S A 92(11), 5087-5091 (1995). doi:https://doi.org/10.1073/pnas.92.11.5087

122. Di Biase, E., Lunghi, G., Fazzari, M., Maggioni, M., Pome, D.Y., Valsecchi, M., Samarani, M., Fato, P., Ciampa, M.G., Prioni, S., Mauri, L., Sonnino, S., Chiricozzi, E.: Gangliosides in the differentiation process of primary neurons: the specific role of GM1oligosaccharide. Glycoconj J 37(3), 329-343 (2020). https://doi. org/10.1007/s10719-020-09919-x

123. Svennerholm, L.: Designation and schematic structure of gangliosides and allied glycosphingolipids. Prog Brain Res 101, XIXIV (1994). doi:https://doi.org/10.1016/S0079-6123(08)61935-4

124. Chester, M.A.: IUPAC-IUB Joint Commission on Biochemical Nomenclature (JCBN). Nomenclature of glycolipids--recommendations 1997. Eur J Biochem 257(2), 293-298 (1998). https://doi.org/10.1046/j.14321327.1998.2570293.x

125. Kumagai, K., Hanada, K.: Structure, functions and regulation of CERT, a lipid-transfer protein for the delivery of ceramide 
at the ER-Golgi membrane contact sites. FEBS Lett 593(17), 2366-2377 (2019). https://doi.org/10.1002/1873-3468.13511

126. D’Angelo, G., Polishchuk, E., Di Tullio, G., Santoro, M., Di Campli, A., Godi, A., West, G., Bielawski, J., Chuang, C.C., van der Spoel, A.C., Platt, F.M., Hannun, Y.A., Polishchuk, R., Mattjus, P., De Matteis, M.A.: Glycosphingolipid synthesis requires FAPP2 transfer of glucosylceramide. Nature 449(7158), 62-67 (2007). https://doi. org/10.1038/nature06097
127. Sandhoff, R., Sandhoff, K.: Emerging concepts of ganglioside metabolism. FEBS Lett 592(23), 3835-3864 (2018). https://doi. org/10.1002/1873-3468.13114

Publisher's Note Springer Nature remains neutral with regard to jurisdictional claims in published maps and institutional affiliations. 